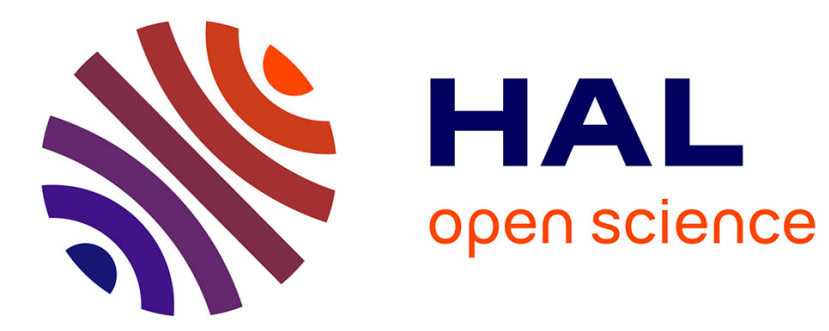

\title{
Methodological approaches to the investigation of musical timbre
}

\author{
A. Melka
}

\section{To cite this version:}

A. Melka. Methodological approaches to the investigation of musical timbre. Journal de Physique IV Proceedings, 1994, 04 (C5), pp.C5-569-C5-576. 10.1051/jp4:19945121 . jpa-00252797

\section{HAL Id: jpa-00252797 https://hal.science/jpa-00252797}

Submitted on 1 Jan 1994

HAL is a multi-disciplinary open access archive for the deposit and dissemination of scientific research documents, whether they are published or not. The documents may come from teaching and research institutions in France or abroad, or from public or private research centers.
L'archive ouverte pluridisciplinaire HAL, est destinée au dépôt et à la diffusion de documents scientifiques de niveau recherche, publiés ou non, émanant des établissements d'enseignement et de recherche français ou étrangers, des laboratoires publics ou privés. 


\title{
Methodological approaches to the investigation of musical timbre
}

\author{
A. MELKA \\ VUZORT a.s., Plzeñská 66, Praha 5, CZ 151 24, Czech Republic
}

\begin{abstract}
Most of the difficulties connected with verbal determination and quantification of the phenomenon called "timbre" or "sound color" are caused by the multidimensional nature of this perceptual attribute of sound. After giving a brief historical review of the methodological evolution of the research on the perception of musical timbre, this paper illustrates some of the appropriate psychoacoustical research methods and associated statistical techniques by use of examples from the investigations of trombone timbre and overall sound quality made in VUZORT, Prague in the course of the last decade. The verbal timbre descriptions obtained in a postal survey and through interviews, as well as the non-verbal data (gained both in a series of listening tests and through the spectral analysis of trombone tones), were processed by various multivariate statistical methods such as hierarchical clustering, factor analysis, multidimensional scaling, multiple linear regression, etc. The resultant findings are compared and discussed.
\end{abstract}

\section{INTRODUCTION}

In the internationally accepted terminology of the International Electrotechnical Commission (IEC) from the year 1984, "timbre" is defined as "that attribute of auditory sensation which enables a listener to judge that two sounds, similarly presented and having the same loudness and pitch, are dissimilar" [1]. This operationalistic formulation defining the term timbre only in a negative way has been adopted almost literally from the terminology of the American standards Association (ASA) published in 1960 [2].

Both of these definitions make use of a general term "sound", but from their formulation it logically follows that the definition range can involve only the sounds enabling the listener to compare their pitches, i.e. sounds having tonal character. There is an ever growing need in modern, especially electronic music, for being able to classify and quantify the "color" of any kind of sound usable in music. This also includes sounds with non-tonal character. We often find the need to compare the "colors" of tones not having the same loudness and/or pitch (usually variable throughout their duration) or even to assess the overall "tonal quality" of a musical instrument. In situations such as these, the definitions just mentioned fail completely. However, it is not the aim of this paper to criticize the standards of acoustical terminology which, after all, only reflectthe current and indeed unsatisfactory state of knowledge in this case. I only 
want, at the very outset, to call the reader's attention to the extraordinary intricacy, difficult determinability and conceptual expressibility of the phenomenon, which is called in different countries by one of the following, rather confusing terms: "die Klangfarbe", "timbre", "sound quality", or by its counterpart in other languages. In fact, all of these terms are relatively young, they appeared only at the turn of the 18th and 19th centuries. F.F. Chladni states in his "Acoustics" that in the year 1802 "there is no name in German for this modification of a particular sound" [3].

\section{HISTORICAL SURVEY}

The history of sound timbre research is usually dated from the year 1863 in which the famous work "Die Lehre von den Tonempfindungen" written by the pioneer in musical acoustics and psychoacoustics $\mathrm{H}$. von Helmholtz was published [4]. Only from the beginning of this time can the presence of two philosophically and methodologically dissimilar approaches be observed [5]. The first could be named the psychophysical approach and corresponds to the positivistic philosophical orientation of Helmholtz. It stems from the conviction that the physical, physiological and psychical processes are divisible into mutually relevant elements and that consequently, undisputed direct relationships between the acoustic stimuli and their sensations exist. The first representative of the second, more psychological approach is $c$. Stumpf [3], who was the next great personality in musical acoustics after Helmholtz. In his opinion, there is neither an explicit nor constant relationship between stimulus and sensation and, moreover, perception of more complicated phenomena can not be explained by means of their resolution into single elements. Through this approach, stumpf prepared the field for bringing "Gestalt psychology" into psychoacoustics, from then, this approach dominated for decades (see e.g. [6]-[8]).

During the next evolutionary phase of timbre investigation these differences resulted in a detachment into two separate research branches: the physical-acoustical and the musical-psychological. While the first one places emphasis on experiment, the second branch, especially in Europe, leans more and more to phenomenological and introspective methods. The situation changed after World War II. Since that time, both of these tendencies have been coming together. Psychophysical techniques are applied to the search and explanation of the relationships between the physical structures of musical sounds and the perceptual structures of musical timbres. Some parts of Gestalt psychology, the psychology of learning and the theory of human information processing, are used for the exploration of the meaning of the structures in a musical context. Here also the individuality of the istener, including his or her historical, social, ethnical and cultural predetermination, has to be taken in account [9].

In contrast to loudness and pitch, timbre has received relatively little attention until the post-war period. Even in 1970 could Plomp [10] state rightly that rather meagre progress had been made in this field in the century since the issue of Helmholtz's works. Certainly, this is connected to the multidimensionality of sound timbre. UnIike the other two perceptual sound attributes - pitch and loudness - timbre cannot be described completely by means of a single scale.

The techniques and means making the analysis of multidimensional phenomena possible, first became available only in the 1960s. In the psychoacoustical research of the post-war period a massive application of psychological tests and questionnaires has been typical. The technique of semantic differential, formalized by osgood [11] and expanded as "polarity-profile method" by Hofstätter [12] in Europe, quickly found many applications. The products of this technique are usually subsequently processed by means of factor analysis. This method was introduced into psychology in the beginning of this century by spearman [13], expanded intensively in the thirties [14] and was more fully developed in the forties by Thurstone [15]. The articles [16]-[18] of the seventies should be mentioned as interesting examples of the applications of this method in timbre research. 
Probably an even stronger influence on timbre research came from a series of original studies on multidimensional scaling methods [19]-[22] published in the sixties. Applications of the methods, the conception of which took place in the second half of thirties [23], quickly appeared in Europe [24]-[29] as well as in the United states [30]-[32] in the seventies.

Concurrently with the evolution of multidimensional scaling methods, the development of cluster analysis methods was taking place. This, as well, started in the thirties [33]. A response in musical psychoacoustics found two methods of hierarchical clustering developed by Johnson [34].

Together with the multivariate analysis techniques referred to above, multiple linear regression procedures should also be mentioned. These are suited to describing the relationships between specific perceptual dimensions of sound color and the overall evaluation of the sound $[35]$. They can also be used to predict the overali sound quality from the relevant physical sound parameters.

Acceleration in the development of multivariate statistical techniques in the sixties and the subsequent, speedy introduction of them into research practise in the following decades is, without any doubt, related to the rapid advance in computer technology and to the fact that computers became widely accessible in western countries in this same time period.

Paralleliing this, advances in digital technology and digital equipment for signal analysis and synthesis influenced the development of a new, non-traditional approach to the exploration of timbre through the "analysis and synthesis method". This approach makes it possible to generate synthetic versions of original musical sounds and, through the control of the synthesis, to extract the perceptually relevant features of the signal under analysis. This method not only provided a better understanding of the physical correlates of timbre, but also made it possible for composers of modern music to compose not only with timbres, but also to create new timbres. A description of the "analysis and synthesis" approach is made by Risset and Wessel in [36].

Human speech science has been a valuable source of inspiration for musical timbre research. Namely, some of the findings concerning vowel perception seem to be - although with some caution - applicable to questions of musical sound color [37].

\section{EXAMPLES}

Now that I have given a brief survey of the most important methods applied in the musical acoustics research of sound timbre, I would like to try to illustrate a few of them by using examples from the perception research of timbre and sound quality of tenor trombones made at vuzorT Prague in the eighties. Besides the research results themselves, the experience obtained with the applied methods and techniques will be mentioned.

In spite of the fact that the ability of any language to express the timbre of a sound by verbal categories satisfactorily is limited, verbal approaches to the research on the perception of musical timbre are very frequent. Indeed, it can be very useful to collect a list of terms (mostly adjectives) used to describe the timbre of explored sounds by a representative sample of subjects in the beginning of a timbre investigation. We were interested in the "timbre vocabulary" of czech professional trombone players playing in a symphony and/or in an opera orchestra. Two techniques for word collection were employed: questionnaire and interview.

In a postal survey [38], 185 trombone players from 36 orchestras were questioned. Only 31 replies from 30 of the orchestras were received, but almost all of them represented the opinions of the entire trombone section of the orchestra. The respondents were asked (among other questions) to enumerate, to the extent possible, pairs of words or word groups which have an opposite meaning and are used by the 
player to describe the tonal qualities of tenor trombones (e.g. "bright" - "dark"; "sharp", "cutting", "edgy" - "dull", "obtuse", "round"). The respondents ísted 52 different adjectives which were then arranged both alphabetically and according to their frequency in response. Then the responses were processed by both methods of hierarchical clustering (HICLUS) described in [34], i.e. the Minimum and the Maximum Methods. The data on the similarities among the paired adjectives were obtained in an indirect manner as applied earlier in [28]: Each time two adjectives were given by a respondent as synonyms, the appropriate pair was given a positive point on a similarity scale. A pair having an opposite meaning was aliotted a negative point. By using this procedure, six different levels of similarity ( $2 ; 1 ; 0 ;-1 ;$ $-2 ;-3)$ were produced. Approximately 97\% of all possible pairs had a neutral level. The results of the Minimum Method appeared to be more meaningfully interpretable than the Maximum Method results. In the first step of the clustering process the adjectives "clear" and "sharp", merged into a cluster. In the following step, six other clusters arose (e.g. "solid" and "full" or "sawing", "cutting" and "razorblade-like"). In the third step, the seven clusters obtained, containing a total of 52 words, merged into one cluster.

The "listen and describe" interview technique was applied as a part of the listening tests [39] and [40] in which ten competent subjects juaged the sound quality of eleven different models of tenor trombones in two musical contexts. Two musical phrases, "M" and "S", representing two dissimilar dynamics and kinds of play were played on each of the instruments with the same loudness by a professional trombone player using his own mouthpiece, and recorded. The recordings were judged by each listener inividually during two listening tests (one for each musical context). A method of pair comparisons was applied. Immediately after judging which of two newly presented instruments had better overall sound quality, the listener was asked to give reasons for his judgment. The 133 various terms used in these commentaries were noted by the test administrator present in the listening room.

Excluding woras expressing rather the perceived "responsiveness" than sound quality of the instruments and merging some almost identical synonyms into the common categories we ordered the remaining 117 terms into an alphabetic and frequency vocabulary for each of the musical contexts.

Several of these terms were used in such a way as to suggest that the words were close in meaning. Each time this happened, the appropriate pair was given a positive point on a similarity scale. After excluding pairs with extremely small frequency, the data were processed using the HICLUS methods [34]. The Maximum Method appeared to give a more meaningful representation than the Minimum Method in both musical contexts. The main clusters obtained in the hierarchical clustering schemes were much more distinct than the clusters obtained from the postal survey data. More than half of the adjectives involved in the main clusters occurred simultaneously in both musical contexts, one of the main clusters had the identical structure ("round", "big") in both contexts. Subtle but distinct differences in meaning between the mutually corresponding main clusters in both schemes were related meaningfully to the specific acoustic and aesthetic features of the phrases "M" and "S".

The results of our analyses on the verbal data collected by two different techniques suggested that the spontaneous verbal descriptions given in listening contexts by an even relatively small number of competent judges, can gain richer and more aistinctive information about timbre than terms collected from a larger number of responses in a postal survey.

Another way of deriving the structure of the verbal attributes of timbre can be by applying factor analysis (FA). The purpose of FA is to reduce a large number of observed variables to a small number of inferred fundamental factors which are amenable to interpretation. In our application [39]-[41] the observed variables were the frequencies of the adjectives used to describe the sound quality of each of 11 trombones during the tests mentioned above. 
The method of principal components and Varimax rotation of the factor axes were applied separately for each musical context. They provided two "best" three-factor solutions which accounted for $71 \%$ of the total variance in both cases. $41 \%$ and $39 \%$ of the total variance (for the musical contexts "M" and "S", respectively) was extracted by the first factor F1, 22\% and $23 \%$ by the factor F2, and only $8 \%$ and $9 \%$ by F3. Two first factors were interpretable without considerable problems. The first factor was represented by the adjectives "soft" $(-0.94)$, "round" $(-0.92)$, "carries well" $(-0.88)$ vs. "rude" (0.88), "sharp" (0.84) and "narrow" (0.76) and interpreted as "softness/roundness vs. rudeness/sharpness" for the phrase "M", and represented by the words "wide" (-0.87) and "round" (-0.86) vs. "sharp" (0.96), "narrow" (0.94) and "cracking" (0.93) and interpreted as "wideness/ roundness vs. sharpness/ narrowness" for the phrase "S". (The numbers in parentheses give the factor loadings). The factor $F 2$ was characterized by the terms "clear" (0.96) and "wide" (0.75) vs. "veiled" $(-0.93)$ and interpreted as "clearness vs. veiling" for " $M$ ", and characterized by the words "clear" (0.84) and "concrete" (0.74) vs. "not ringing" $(-0.88)$ and "veiled" $(-0.81)$ and interpreted as "clearness vs. veiledness" for "s". We did not succeed in interpreting meaningfully the third factor which tended to split into two subfactors.

In a close agreement with the results of the HICLUS analyses described earlier, small but clear shifts in the meaning of the corresponding factors in both musical contexts were found related to the specific features of them. ("M" was a trombone cantilena from a concert for trombone and symphony orchestra played by a soloist in mezzoforte, "S" was a trombone part of an orchestral tutti phrase played by the same player in ff).

Even though the results of the attempts to understand the structure of perceptual trombone timbre space described in the last paragraph offered very useful information, they also showed the limits of the verbal approach. For this reason we tried to apply some non-verbal methods as well.

one of them - the already mentioned psychometric method of pair comparisons - offered the overall evaluations of the sound quality of the trombones. As a result of this, the trombones under test were ordered on an ordinal scale of overall sound quality. (Let me remark that the experimental technique used made it possible for listener to optimize the test procedure according to his needs, which was found in a similar context - to make it far superior to other scaling procedures such as "usual" pair comparison, triadic comparison, ranking and rating [42]).

Another non-verbal psychometric method we used was the direct scaling of the perceived timbre similarity between the sound stimuli presented in pairs on a graphical scale graded from an "extremely small" to an "extremely large" similarity. The listeners, trombone recordings and the test arrangement were the same as in the preference tests described above. The similarity judgments obtained for each pair of trombones were processed by the method of multidimensional scaling (MDS)

The purpose of MDS is to represent similarities among a set of objects (e.g. sound stimuli) by distances in a multidimensional space and to find patterns and constituent dimensions of a multidimensional phenomenon (e.g. perceived sound quality) in the empirical data which would otherwise remain hidden. (This purpose could be much better expressed by the name "Multidimensional Similarity structure Analysis" SSA) used in [43], but the term MDS is now well-established).

The basic non-metric model using a monotonic transformation and a simple Euclidean distance model was applied on both sets of our similarity data. Computation of the best-fitting configuration of points according to [21] indicated that the data could be represented satisfactorily in the three-dimensional space of instruments. Adding one more dimension would reduce the original "stress" values (Kruskal's "badness-of-fit" measure [20]) - 13\% for the phrase "M" and 8\% for "S" - only at a small rate. our attempts to interpret the computed threedimensional solutions only from the original data were not successful 
(among other things, we submitted the same data to HICLUS analysis and tried to use this to interpret the scaling solution). For this reason, we tried to use an external source of information for interpreting the meaning of the configurations. The subjects' comments on the sound quality of 11 trombones, expressed during the preference tests, were believed to be suitable information for this purpose. Excluding first the adjectives which occurred less often than ten times, we applied a procedure for "embedding" the remaining "properties" (26 and 27 adjectives for " $M$ " and "S" respectively) as vectors in the two solution spaces [44], [39] and [41]. The aim of this procedure was to position the property vector in the timbre space of instruments so that the projections of the instruments onto the vector correlate as closely as possible with the property values (i.e. the occurrance frequencies of the adjective concerned by different instruments). This succeeded at 17 and 15 properties for "M" and "S" respectively. We then tried to sort the vectors with high positive and negative inter-correlations into a smaller number of groups of properties. Four such groups of vectors were found and each of them was represented then by a "property-axis" crossing the origin of the 3-dimensional instrument space and being, unlike vectors, bipolar.

The first property-axis Al (fitted into the space with the correlation coefficient $r=0.96$ ) involved the properties described by the terms "soft" $(0.91)$, "round" (0.90), "carries well" (0.87) and "big" $(0.77)$ vs. "not-outstanding" $(-0.88)$, "rude" $(-0.87)$, "narrow" (-0.85) and "flat" $(-0.78)$ for the musical context " $M$ " and (fitted with $r=$ $0.89)$ the properties "full" $(0.91)$, "round" $(0.84)$ and "wide" $(0.74)$ vs. "narrow" $(-0.85)$ for the phrase "S". The axis A2 (with $r=0.87$ ) was characterized by the properties "ringing" $(0.89)$ vs. "sharp" $(-0.78)$ and "not ringing" $(-0.75)$ for "M", and (with $r=0.87$ ) by the adjectives "big" $(0.65)$ vs. "sharp" (-0.85), "thin" $(-0.84)$, "cracking" $(-0.83)$ and "penetrating" $(-0.77)$ for "S". The axis A3 involved (fitted with $r=0.96$ ) the properties "wide" $(0.97)$ and "clear" $(0.84)$, vs. "veiled" $(-0.87)$ for "M", and (with $r=0.85)$ the adjectives "clear (0.77)" vs. "not ringing" (-0.80) and "veiled" $(-0.76)$ for "S". The last axis A4 involved (with $r=0.96$ ) the terms "rich" $(0.70)$ and "full" $(0.70)$ vs. "not rich enough" $(-0.85)$ for "M", and (with $r=0.92$ ) the terms "concrete" (0.82) and "soft" (0.79) vs. "hard" $(-0.85)$ for "S".

Comparing these results with the results obtained from the FA we observe many similarities between both of them. In all of our FA and MDS solutions the optimal number of extracted factors/dimensions was found to be three. Only two clear interpretable factors/axes were obtained from each solution: the orthogonal factors $F 1 \perp F 2$ and the property axes A1, A3 including angles not very different from the right angle ( $81^{\circ}$ for "M" and 70 for "S"). Moreover, a very close concordance of meaning was found between $F 1$ and $A 1$ as well as between $F 2$ and A3 in both musical contexts.

The combined results of all three multivariate procedures (HICLUS, FA, MDS) which we applied to the data, got from the listening tests, suggest the following perceptual dimensions in sound color of trombones under research [41]:

1) "roundness/softness vs. sharpness/narrowness" for musical context "M" or "wideness/roundness vs. narrowness/sharpness" for "S"; 2) "clearness/wideness vs. veiledness" for "M" or "clearness/ concreteness vs. veiledness/not ringing" for "S".

The terms on the left and right sides of each opposite pair written above correlated highly positively (negatively) with the overall sound quality, respectively. It should be remembered that "M" was a cantabile playin mezzoforte, while "S" represented a tutti kind of play in fortissimo.

Using multiple linear regression we found that the overall sound quality of a tenor trombone could be sufficiently described by means of the two dimensions named above as follows [41]:

and

quality $=0.28$ roundness +0.13 clearness $+0.63 \ldots$ for "M",

quality $=0.26$ wideness +0.12 clearness $+0.55 \ldots \ldots$ for "S". 
An important piece of information usable both in interpreting the meaning of a perceptual space derived from the sound color's similarities among a set of instruments and in predicting the different perceptual dimensions, or the overall sound quality from the objective data, is hidden in the sound spectra of the instruments. It is generally thought that - at least with quasi-stationary sounds - timbre depends primarily upon the amplitude spectrum of the sound [1], [26] . As many research studies had shown, the most appropriate approach is to convert each amplitude spectrum into a distribution of "Bark spectra", i.e. spectra distributed in "critical bands" or Bark bands as applied by 2 wicker [48]. In our work we applied the "standard Bark spectra" (see [45-47], [40] and [49]) of 11 trombone models mentioned above, each computed as an average of the amplitude spectra, separately for three playing dynamics ( $\mathrm{pp}, \mathrm{mf}, \mathrm{ff}$ ) and four tonal registers, of 35 semitones covering the tonal range of tenor trombone. We attempted to predict both the overall sound quality and the specific sound qualities we obtained ("roundness", "clearness", "wideness") of a tenor trombone using two different predictors [41]. One of these was constructed by means of stepwise multiple regression (SMR) of Bark band levels, the other was derived from the factor scores resulting from FA applied on the Bark level values. Both of the predictors seemed to have an acceptable reliability and accuracy in predicting the overall sound quality. As regards predicting the specific timbre qualities, the power of the predictors could not be checked because of a lack of appropriate perceptual judgments.

Despite the fact that most of the research findings described in this chapter show a surprising amount of consistency, we should refrain from any inappropriate generalizations because the results are strongly dependent upon the representativeness of the instrument sets, musical passages and subject samples used in the experiments. To check the reliability of the results obtained and to confirm the validity of them in a broader context, an additional series of experiments would be necessary.

\section{ACKNOWLEDGMENT}

The work on this paper has been, in part, supported by the Research Grant No 202/93/2522 from the Grant Agency of the Czech Republic.

\section{REFERENCES}

[1] IEC (International Electrotechnical Commission), International Electrotechnical Vocabulary (CEI, 1984), Def. No 801-09-09.

[2] ASA (American Standards Association), American Standard Acoustical Terminology (1960), S I.I-1960.

[3] Stumpf C., Tonpsychologie I-II (S. Hirzel Verlag, Leipzig, 1883, $1890)$.

[4] Von Helmholtz H., Die Lehre von den Tonempfindungen (Friedr. Vieweg \& Sohn, Braunschweig, 1863).

[5] Bláha M. and Léb1 V., Hudebni vĕda 11 (1974) 211-249, (in Czech, with English résumej)'

[6] Kurth E., Musikpsychologie (Max Hesses Verlag, Berlin, 1931).

[7] Révész G', Einführung in die Musikpsychologié (A. Francke Verlag, Bern, 1964).

[8] Wellék A., Musikpsychologie und Musikästhetik (Akademische Verlaggesellschaft, Frankfurt am Main, 1963).

[9] Sirker U., "The timbre in music and its significance for musical hearing", 44th AES Convention, Rotterdam 20-22 February 1973.

[10] Plomp R.', "Timbre as a multidimensional attribute of complex tones". In: Plomp R. and Smoorenburg G.F. (eds.), Frequency analysis and periodicity detection in hearing (Sijthoff, Leiden, 1970) pp. 397-414. 
[11] Osgood C.E. et al., The measurement of meaning (University of Ilinois Press, Urbana, 1957).

[12] Hofstätter P.R., Einführung in die quantitativen Methoden der Psychologie (München, 1955).

[13] Spearman C Amer. J. Psychol. 15 (1904) 201-293.

[14] Hotelling H., J. Educ, Psychol. 24 (1933) 417-441.

[15] Thurstone L.L., Multiple Factor Analysis (University of chicago Press, Chicago, 1947).

[16] Von Bismarck G., Acustica 30 (1974) 146-159.

[17] Plomp R. and Steeneken H.J.M., Acustica 28 (1973) 49-59.

[18] Plomp R., in: Var hörsel och musiken (Kungl. Musikaliska Akademien, Stockholm, 1979), in Swedish.

[19] Shepard R.N., Psychometrika 27 (1962) 125-140 and 219-246.

[20] Kruskal J.B., Psychometrika 29 (1964) 1-27.

[21] Kruskal J.B., Psychometrika 29 (1964) 115-129.

[22] Carroll J.D. and Chang J.J., Psychometrika 35 (1970) 283-319.

[23] Richardson M.W., Psychol. Bull. 35 (1938) 659.

[24] Plomp R. and Steeneken H.J.M., J. Acoust. Soc. Amer. 46 (1969) $409-421$.

[25] Wedin I. and Goude G., Scand. J. Psychol. 13 (1972) 228-240.

[26] Plomp R., Aspects of tone sensation (Academic Press, London, 1976) pp. 93-97.

[27] de Bruijn A., Acustica 40 (1978) 108-114.

[28] Edwards R.M., J. Sound and Vibration 58 (1978) 407-424.

[29] Gabrielsson Á. and Jansson E. Acustica 42 (1979) 47-55.

[30] Miller J.R. and Carterette E.C., J. Acoust. Soc. Amer. 58 (1975) $711-720$.

[31] Grey J.M., J. Acoust. Soc. Amer. 61 (1977) 1270-1277.

[32] Grey J.M. and Gordon J.W., J.ACoust. SoC. Amer. 63 (1978) 14931500 .

[33] Tryon R.C., Cluster Analysis (Edwards Bros., Ann. Arbor, 1939).

[34] Johnson S.C., Psychometrika 32 (1967) 241-254.

[35] Gabrielsson A. "Problems and methods in judgments of perceived sound quality", 102nd ASA Meeting, Miami Beach, 30 November - 4 December 1981 .

[36] Risset J.-C. and Wessel D.I., "Exploration of timbre by analysis and synthesis". In: Deutsch D. (ed.), The psychology of music (Academic Press, Orlando, 1982) pp 25-58.

[37] Slawson $W .$, sound Color (University of California Press, London, 1985) pp 144-164.

[38] Melka A., Research report No 5/1980 (VÚzoRT, Prague, 1980) pp 1253 , in Czech.

[39] Melka A. and Balogh J., "Die Klangfarbe von Tenorposaunen: Subjektive Untersuchungen", 6th FASE Symposium, Sopron 2-6 September 1986 (Budapest, 1986) pp 129-132.

[40] Melka A., Research report No 23/1985 (VÚzORT, Prague, 1985), in Czech.

[41] Melka A. and Štěpánek J., Research report No 30/90 (VÚzORT, Prague, 1990), in Czech.

[42] Melka A., "Experimentelier Vergleich von fünf Methoden der subjektiven Bewertung der Wiedergabequalität", 2nd FASE Congress, Warsaw 18-22 September 1978.

[43] Borg I. and Lingoes J., Multidimensional similarity structure Analysis (Springer-Verlag, New York, 1987).

[44] Coxon A.P.M., The User's Guide to Multidimensional Scaling (Heinemann Educational Books. Ltd, London, 1982) pp 104-108.

[45] Melka A., Research rep. No 16/82 (VÚzORT, Prague 1982), in Czech.

[46] Melka A. et al., "Long-time-average-spectra of tenor trombones: part I, II, III", 23 rd Czechoslovak Acoustic Conference, České Budějovice 2-4 October 1984 (Dủm techniky, Praha, 1984) pp 148-159.

[47] Bażant P. and Melka A., "Die Klangfarbe von Tenorposaunen: Objektive Untersuchungen", 6th FASE Symposium, Sopron 2-6 September 1986 (Budapest, 1986) pp 17-20.

[48] Zwicker E., Das ohr als Nachrichtenempfänger (S. Hirzel Verlag, Stuttgart, 1967)

[49] Melka, A.' and Bažant, P., Research report No E9/1987 (VúzORT, Prague, 1987), in Czech. 